\title{
Mechanism of Oxidation of Low-Oxygen SiC Fiber Prepared by Electron Radiation Curing Method
}

\author{
Toshio SHIMOO, Toshihide HAYATSU*, Michio TAKEDA**, Hiroshi ICHIKAWA**, \\ Tadao SEGUCHI*** and Kiyohito OKAMURA
}

Department of Metallurgy and Materials Science, College of Engineering, University of Osaka Prefecture, 1-1, Gakuen-cho, Sakai-shi 593

*Graduate Student, University of Osaka Prefecture, 1-1, Gakuen-cho, Sakai-shi 593

**Laboratory, Nippon Carbon Co., Ltd., 1-1, Shin-urashima-cho, Kanagawa-ku, Yokohama-shi 221

***Takasaki Radiation Chemistry Research Establishment, Japan Atomic Energy Research Institute, 1233, Watanuki-machi, Takasaki-shi 370-12

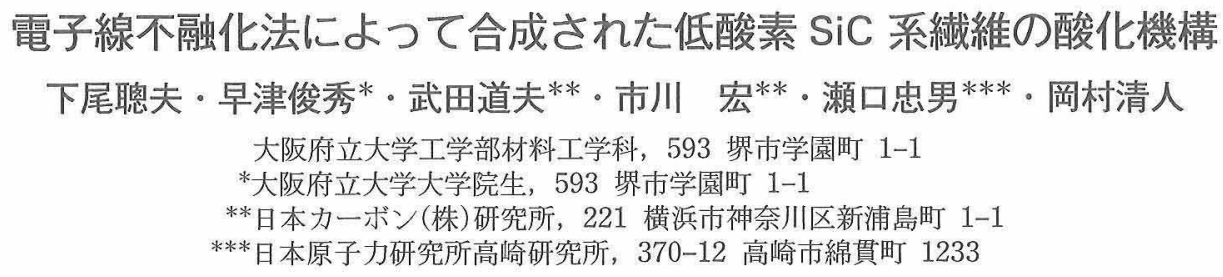

[Received November 22, 1993; Accepted April 5, 1994]

\begin{abstract}
The mechanism of oxidation of a low-oxygen SiC fiber prepared by the electron radiation curing method was investigated. The oxidation rates were measured with a thermobalance in $\mathrm{O}_{2}$ at temperatures from 1373 to $1773 \mathbf{K}$. The reaction products were examined by $\mathrm{X}$-ray diffraction and SEM observation. The oxide film was amorphous silica below $1573 \mathrm{~K}$ and crystallized to cristobalite above $1673 \mathrm{~K}$. The core crystallized to form a trace of $\beta$-SiC, accompanying the formation of amorphous free carbon. The oxide film suppressed the pyrolysis of the core. The oxidation rate obeyed the diffusion-controlled contracting-disc formula. The activation energy was $234 \mathrm{~kJ} / \mathrm{mol}$. The oxidation is considered to be controlled by the gas diffusion through the micropores in the sillica film. The reduction of oxygen content in the polymer-derived SiC fibers is effective not only for suppression of the high-temperature pyrolysis but also for improvement of the oxidation resistance.
\end{abstract}

Key-worols : Electron radiation curing, Low-oxygen SiC fiber, Oxidation rate, Thermogravimetric analysis, Reaction mechanism

1. Introduction

The polymer-derived SiC fibers have been expected for application to metal-based and ceramic-based composite materials as the reinforcing fibers. ${ }^{1)-6)}$ Two types of the fibers are available commercially in Japan; Nicalon (Si-C-O, Nippon Carbon, Co., Ltd.) and Tyranno ( $\mathrm{Si}-\mathrm{Ti}-\mathrm{C}-\mathrm{O}$, Ube Industries, Ltd.). These fibers contain substantial amounts of oxygen derived during the oxidation-curing of polycarbosilane fiber. Consequently, the pyrolysis, which accompanies the generation of $\mathrm{SiO}$ and $\mathrm{CO}$ and the growth of $\beta$-SiC crystals, occurs severely and the tensile strength of the fibers decreases at temperatures higher than $1573 \mathrm{~K}^{7}{ }^{\text {) }}$-9) The reduction of oxygen content is necessary to suppress its high temperature pyrolysis and to improve its strength. The electron radiation-curing method was found to be effective for the reduction of the oxygen as the source of the pyrolysis. The pyrolytic behavior in Ar has been investigated for the low oxygen fiber, which was prepared as a trial product using the electron radiationcuring method. The pyrolytic gases evolved slightly and $\beta$-SiC remained in microcrystalline at elevated temperatures. ${ }^{10)}$-12) The fiber retained about $40 \%$ of the original tensile strength even after heating for $3.6 \mathrm{ks}$ at $1973 \mathrm{~K} .{ }^{12}$ ) Thus, the high temperature properties of the low oxygen fiber was superior to those of Nicalon and Tyranno.

When the fiber is applied in oxidizing atmospheres at high temperatures, the oxidation resistance also is required. We previously examined the oxidation rates of Nicalon and Tyranno, and showed that the rate-determining step was the diffusion of gas through micropores in silica film. ${ }^{13), 14)}$ In addition, it was found that the oxide film formed around the fiber suppressed the pyrolysis of the core by restricting the generation of $\mathrm{SiO}$ and $\mathrm{CO} .{ }^{15)}$-19) The object of present work is to clarify the oxidation mechanism of the low oxygen fiber prepared by the electron-radiation curing method. Using thermogravimetric analysis method, the oxidation rates were determined in $\mathrm{O}_{2}$ atmosphere at temperatures from 1573 to 1773 $\mathrm{K}$. The room-temperature tensile strengths of the fiber were measured after each oxidation. The observed variation in strength was related to the morphology of the fiber and the $\beta$-SiC crystal size in the fiber.

2. Experimentals

Original fiber is $\mathrm{SiC}$ fiber prepared as a trial 
product by the electron-radiation curing method and contains 0.85 mass $\% \mathrm{H}$. This fiber was heat-treated in $\mathrm{N}_{2}$ for $18 \mathrm{ks}$ at $1373 \mathrm{~K}$ in order to ceramize sufficiently. Thus, the low-oxygen fiber used in this study has a composition of $\mathrm{SiC}_{1.40} \mathrm{O}_{0.05}$ and an average diameter of $15 \mu \mathrm{m}$.

The thermobalance unit used to determine the oxidation rate of the fibers consists of an analogue-type autorecording balance (measurable limit: $100 \mathrm{~g}$, sensivity : $0.1 \mathrm{mg}$ ) and a $\mathrm{SiC}$ resistance furnace.

The experimental temperature was measured with a $\mathrm{Pt}-6 \% \mathrm{Rh} / \mathrm{Pt}-30 \% \mathrm{Rh}$ thermocouple positioned close to the sample. When the desired temperature was reached, $\mathrm{O}_{2}$ was flowed from the bottom of the furnace at $8.8 \times 10^{-6} \mathrm{~m}^{3} / \mathrm{s}$. Fibers of $1 \mathrm{~g}$ in mass and $3 \mathrm{~cm}$ in length were charged in a magnesia crucible of $26 \mathrm{~mm}$ in diameter and $35 \mathrm{~mm}$ in depth. The crucible was suspended in the hot zone of a furnace (alumina reaction tube of $44 \mathrm{~mm}$ in inner diameter) with an alumina rod and a platinum wire to the balance. The mass gain was recorded automatically during each oxidation. Upon completion of the TGA measurement, the fibers were cooled rapidly by raising the crucible to the low temperature zone of the furnace. The crystal structure of the reaction products were identified by an X-ray diffraction (XRD), and the morphology of the fiber was observed by a scanning electron microscope (SEM). Furthermore, the tensile strength of the fiber was measured as follows:

The oxide layer was removed with $\mathrm{NH}_{4} \mathrm{~F}+\mathrm{HF}$ solution. Using a load cell of $100 \mathrm{~g}$, the tensile test of a monofilament fiber of $10 \mathrm{~mm}$ in gauge length was carried out on a Tensilon-type machine (Toyo Measuring Instrument, Co., Ltd., Type UTM-II-20) at a crosshead speed of $2 \mathrm{~mm} / \mathrm{min}$.

\section{Results}

\subsection{TGA measurement}

Figure 1 shows TGA curves for the fiber heated isothermally in $\mathrm{O}_{2}$ at temperatures from 1373 to $1773 \mathrm{~K} . \Delta W / W_{0}$ is the ratio of the mass gain determined by a thermobalance to the initial mass of the fiber. The mass gain observed is due to the following overall oxidation reaction:

$$
\begin{gathered}
\mathrm{SiC}_{1.40} \mathrm{O}_{0.05}(\mathrm{~s})+2.375 \mathrm{O}_{2}(\mathrm{~g}) \\
\quad=\mathrm{SiO}_{2}(\mathrm{~s})+1.40 \mathrm{CO}_{2}(\mathrm{~g})
\end{gathered}
$$

The TGA curves show a parabolic feature characteristic of a diffusion-controlled reaction.

\subsection{X-ray diffraction analysis}

Figure 2 shows the diffraction patterns of the fiber oxidized for $72 \mathrm{ks}$ at temperatures from 1373 to $1773 \mathrm{~K}$. Below $1573 \mathrm{~K}$, the oxide film formed around the fiber is composed of wholly amorphous silica. This is characterized from a broad pattern at $2 \theta$ $\doteqdot 22^{\circ}$. The oxide film crystallize to cristobalite with increasing oxidation temperature.

Original fiber considerably contains hydrogen and is incompletely ceramized (A). An XRD pattern of the fiber fired at $1373 \mathrm{~K}$ is broad and suggests the microcrystalline state of $\beta$-SiC (B). Because of the crystallization to $\beta$-SiC, the XRD pattern becomes sharper gradually with increasing temperature $(\mathrm{C}-$

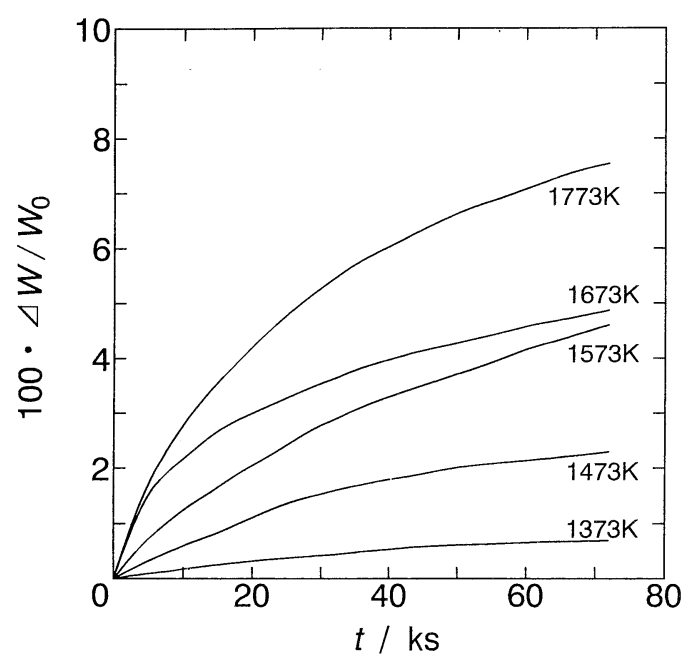

Fig. 1. Mass gain with oxidation of low-oxygen fiber at various temperatures.

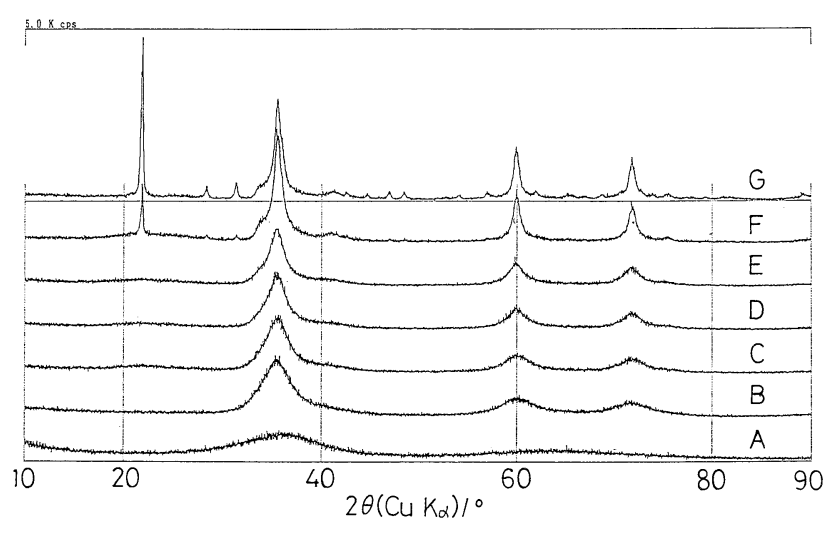

Fig. 2. X-ray diffraction patterns of original low-oxygen fiber (A), fiber fired at $1373 \mathrm{~K}(\mathrm{~B})$ and fibers oxidized at $1373 \mathrm{~K}(\mathrm{C})$, $1473 \mathrm{~K}(\mathrm{D}), 1573 \mathrm{~K}(\mathrm{E}), 1673 \mathrm{~K}(\mathrm{~F})$ and $1773 \mathrm{~K}(\mathrm{G})$.

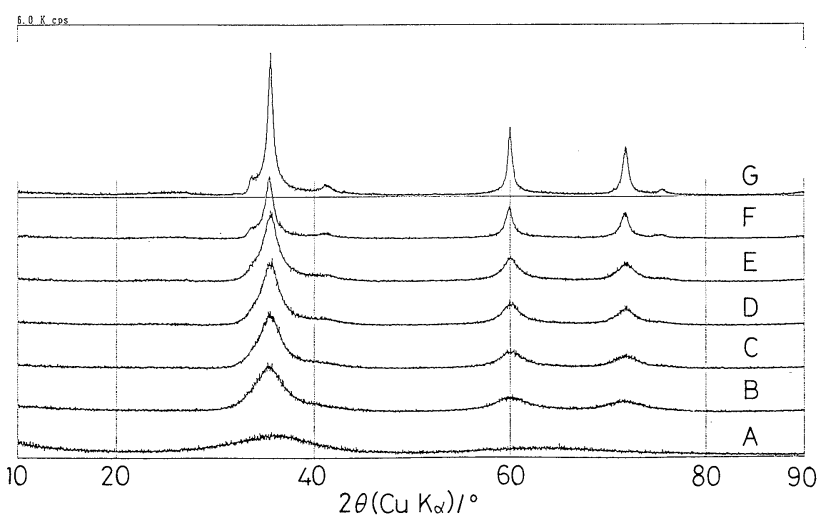

Fig. 3. X-ray diffraction patterns of original low-oxygen fiber (A), fiber fired at $1373 \mathrm{~K}(\mathrm{~B})$ and fibers oxidized at $1373 \mathrm{~K}(\mathrm{C})$, $1473 \mathrm{~K}(\mathrm{D}), 1573 \mathrm{~K}(\mathrm{E}), 1673 \mathrm{~K}(\mathrm{~F})$ and $1773 \mathrm{~K}(\mathrm{G})$. Oxide film was removed with $\mathrm{NH}_{4} \mathrm{~F}+\mathrm{HF}$ solution. 
G). This crystallization can be further clarfied from Fig. 3. This figure shows the diffraction patterns of the fiber, from which the oxide film was removed with $\mathrm{NH}_{4} \mathrm{~F}+\mathrm{HF}$ solution. At temperatures higher than $1673 \mathrm{~K}$, a broad pattern of solid carbon is observed at $2 \theta \fallingdotseq 26^{\circ}$. The formation of $\beta$-SiC and free carbon suggests the occurrence of the following pyrolytic reaction in the core of the fiber during oxidation :

$$
\begin{aligned}
& \mathrm{SiC}_{1.40} \mathrm{O}_{0.05}(\mathrm{~s}) \\
& \rightarrow \beta-\mathrm{SiC}(\mathrm{s})+\mathrm{C}(\mathrm{s})+\mathrm{SiO}(\mathrm{g})+\mathrm{CO}(\mathrm{g})
\end{aligned}
$$

\subsection{SEM observation}

Figure 4 represents scanning electro-micrographs of the surface and the cross section of the fiber oxidized for $72 \mathrm{ks}$ at temperatures from 1473 to $1773 \mathrm{~K}$. The difference in the crystallinity as shown in XRD patterns was reflected in the morphology of the silica film. Below $1573 \mathrm{~K}$, the crack-free film of amorphous silica adhered closely to the core. Above 1673 $\mathrm{K}$, many cracks were observed on the cristobalite film. Sometimes spalling of the film has occurred. Obviously, cracking and spalling did not take place during oxidation, because of the monotonous mass gain

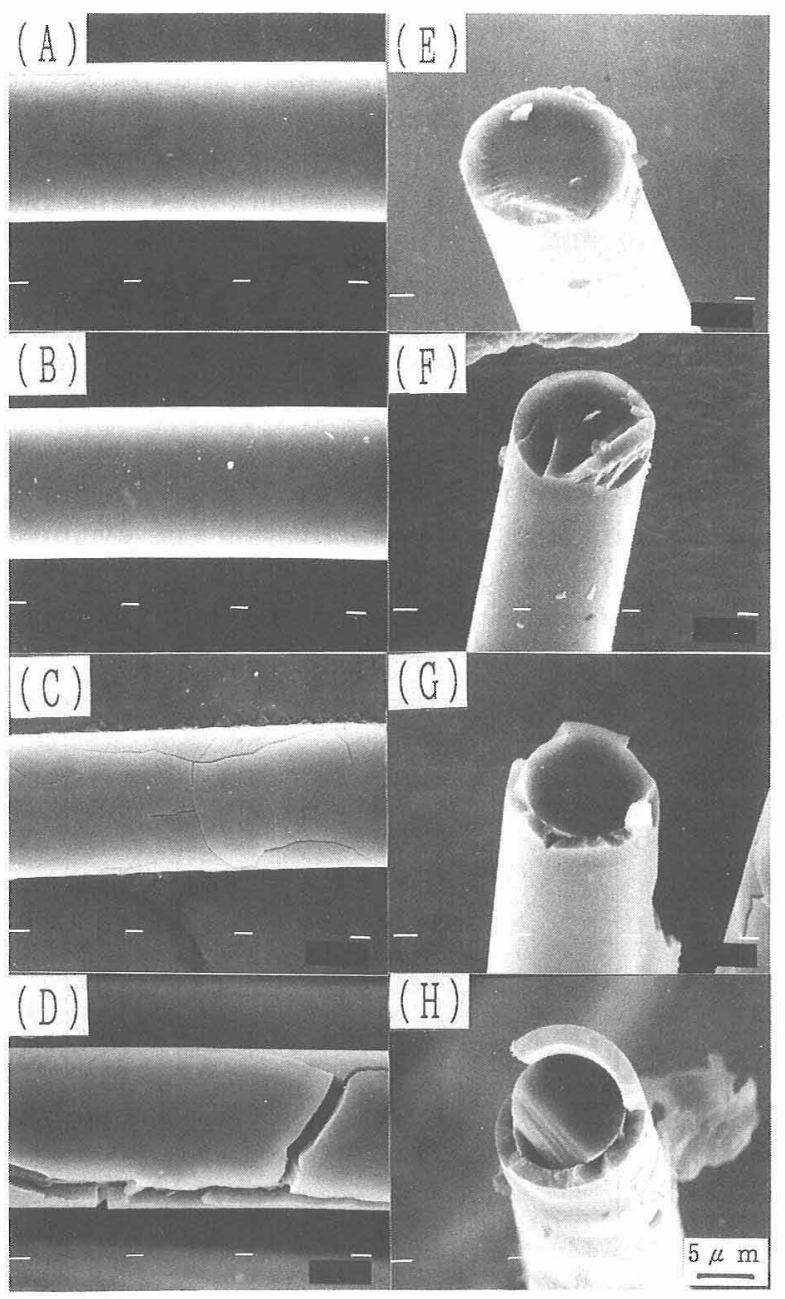

Fig. 4. Surface (A, B, C, D) and cross section (E, F, G, H) of low-oxygen fiber oxidized at $1473 \mathrm{~K}(\mathrm{~A}, \mathrm{E}), 1573 \mathrm{~K}(\mathrm{~B}, \mathrm{~F}), 1673$ $\mathrm{K}(\mathrm{C}, \mathrm{G})$ and $1773 \mathrm{~K}(\mathrm{D}, \mathrm{H})$.

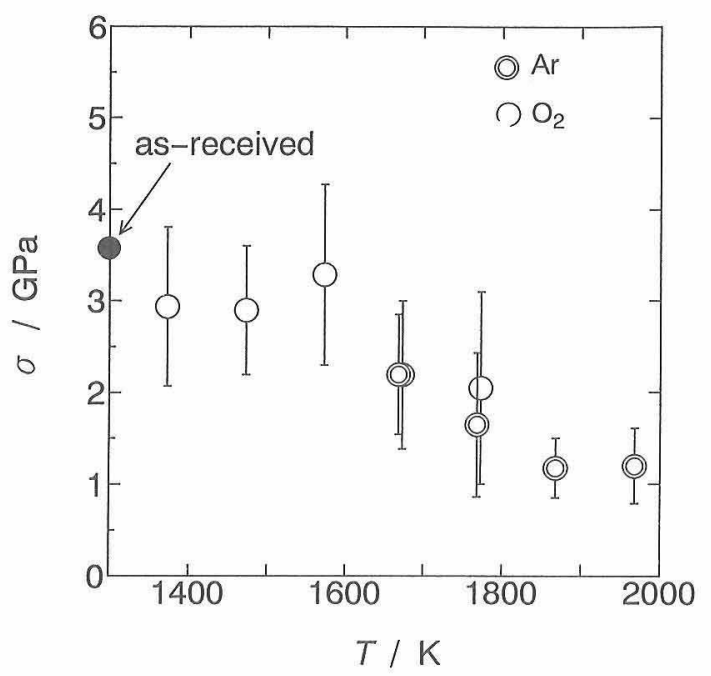

Fig. 5. Tensile strength of low-oxygen fiber heated in $\mathrm{O}_{2}(\mathrm{O})$ and in $\mathrm{Ar}(\mathrm{O})$ at various temperatures. Oxide film was removed with $\mathrm{NH}_{4} \mathrm{~F}+\mathrm{HF}$ solution.

in TGA curves. These are considered to be due to the volume change resulting from $\alpha \rightleftarrows \beta$ transformation of cristobalite on cooling. ${ }^{20)}$ The fracture appearance of the fiber was smooth even at $1773 \mathrm{~K}$. The growth and coarsening of $\beta$-SiC crystals resulting the pyrolysis were not observed in the core.

\subsection{Tensile test}

Figure 5 shows the tensile strength of the fiber oxidized for $72 \mathrm{ks}$, with that of the fiber heated in Ar for $7.2 \mathrm{ks}$ as a function of temperature. The oxide film was removed with the $\mathrm{NH}_{4} \mathrm{~F}+\mathrm{HF}$ solution. The asreceived fiber is that fired in $\mathrm{N}_{2}$ at $1373 \mathrm{~K}$. There is a small decrease in the tensile strength of the fibers oxidized below $1573 \mathrm{~K}$. At $1673 \mathrm{~K}$, the strength is appreciably reduced because of the crystallization of the core to $\beta$-SiC and of the silica film to cristobalite, which will be mentioned in discussion. However, even the fiber oxidized at $1773 \mathrm{~K}$ retained $55 \%$ of the as-received strength. It may be noted that the strength of the fiber oxidized in $\mathrm{O}_{2}$ is nearly the same as that of the fiber pyrolyzed in Ar, despite exceedingly prolonged heating in the oxidation. This may be attributed to the inhibition of the pyrolysis by the formation of silica film. It was previously observed that the silica film suppressed the pyrolysis of Nicalon and Tyranno. ${ }^{15)}-19$ )

\section{Discussion}

\subsection{Oxidation mechanism of fiber}

The model for $\mathrm{SiC}$ fibers shows that $\beta$-SiC intermixed with free carbon in microcrystalline state. ${ }^{21)}$ The oxidation of free carbon results in mass loss, whereas that of $\mathrm{SiC}$ results in mass gain.

$$
\begin{aligned}
& \mathrm{C}(\mathrm{s})+\mathrm{O}_{2}(\mathrm{~g})=\mathrm{CO}_{2}(\mathrm{~g}) \\
& \mathrm{SiC}(\mathrm{s})+2 \mathrm{O}_{2}(\mathrm{~g})=\mathrm{SiO}_{2}(\mathrm{~s})+\mathrm{CO}_{2}(\mathrm{~g})
\end{aligned}
$$

The overall oxidation of the low oxygen fiber is represented by Eq. (1). Because of a little amount of free carbon, the oxidation causes a mass gain in 
total. $\mathrm{SiO}_{2}$ grows as a film towards the center of the fiber. Therefore, the oxidation proceeds through the following basic steps :

(1) Diffusion of $\mathrm{O}_{2}$ from the bulk gas phase through the boundary layer around the fiber.

(2) Diffusion of $\mathrm{O}_{2}$ through the oxide film surrounding around the un-oxidized core of the fiber.

(3) Chemical reaction between $\mathrm{O}_{2}$ and the fiber at the interface between the oxide film and the un-oxidized core of the fiber.

(4) Diffusion of $\mathrm{CO}_{2}$ through the oxide film.

(5) Diffusion of $\mathrm{CO}_{2}$ through the boundary layer. The oxidation rate is expected to be controlled by step (2) or (4), after the fiber was completely surrounded by the oxide film. ${ }^{13), 14)}$ A reaction interface is constantly receding towards the center of the fiber, leaving behind the oxide film. Thus, the effective crosssectional area for diffusion is constantly decreasing, to yield the contracting-disc rate equation for diffusion control ${ }^{22)}$

$$
(1-X) \ln (1-X)+X=k \cdot t
$$

where $k$ is the rate constant, and $X$ is the degree of oxidation and is given from the stoichiometry of the reaction (1) by the equation

$$
X=\Delta W / 0.316 W_{0}
$$

From the rate data shown in Fig. 1, the plots of $(1-X) \ln (1-X)+X$ against time are represented in Fig. 6. These plots indicate that the oxidation rate follows nearly the linear relationship predicted by Eq. (5). At 1673 and $1773 \mathrm{~K}$, deviations are noted from linearity after about $40 \mathrm{ks}$. The reasons for this deviation are stated below.

The fibers was agglomerated into a mass by the adherence of the oxide film, which became thicker after long time oxidation. The same phenomenon was observed for Nicalon and Tyranno. ${ }^{13)}$ Such agglomeration results in the reduction of the effective area for diffusion and decreases the oxidation rate. However, the deviation from Eq. (5) was not observed in the oxidation of Tyranno. Therefore, the oxidation rate

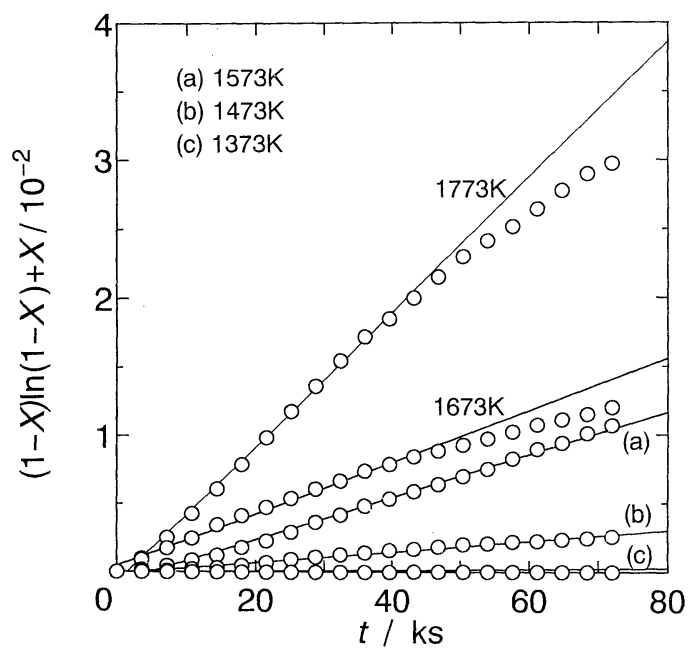

Fig. 6. Application of rate Eq. (5) to data shown in Fig. 1. is hardly affected by the agglomeration of the fibers.

The silica film, which is formed on $\mathrm{SiC}$, is amorphous at the biginning of the oxidation and at low temperatures, and tends to crystallize by the treatment for longer time and at higher temperature. ${ }^{23)}$ As shown in Fig. 3, the oxide film, which surrounds the fiber, crystallizes to cristobalite at temperatures above $1673 \mathrm{~K}$. Crystallization is considered to increase the gas permeability of the oxide film $^{24)}$ and the mismatch of thermal expansion between the fiber and the film. In particular, the latter will form flaws in the film. These led to the generation of pyrolytic gases from the core and the downward curvature from the linearity of Eq. (5). Nicalon tends to pyrolyze severely because of the high oxygen concentration of 13 mass\%. During high temperature oxidation, the high pressure of both $\mathrm{SiO}$ and $\mathrm{CO}$ evolving from the core caused the cristobalite film to fracture easily. As a result, the gases escaped from the core through the flaws of the oxide film at a later stage of the oxidation. Thus, TGA curves for Nicalon NL400 had a maximum, beyond which the mass gain changed to the mass loss. ${ }^{14)}$ Yet, the mass increased monotonously during oxidation of the low oxygen fiber because of sluggishness of the pyrolysis. Finally the slight pyrolysis occurs during oxidation. This is substantiated by the crystallization to $\beta$-SiC (Fig. 3 ) and the decrease in tensile strength (Fig. 5).

Figure 7 represents plots of the rate constant $k$ against the reciprocal of temperature. The plots obey Arrhenius' law. The apparent activation energy was $234 \mathrm{~kJ} / \mathrm{mol}$. This value is in the range from 209 $\mathrm{kJ} / \mathrm{mol}$ to $387 \mathrm{~kJ} / \mathrm{mol}$ as the activation energies for the oxidation of $\mathrm{SiC} .{ }^{25)-29)}$ The species diffusing in the silica film is $\mathrm{O}_{2}$ molecules or oxygen ions. The activation energies of the oxygen ion are $298 \mathrm{~kJ} / \mathrm{mol}$ for the interstitial diffusion and $420 \mathrm{~kJ} / \mathrm{mol}$ for the vacancy diffusion. ${ }^{27)}$ Low activation energy for the oxidation of the fiber is not attributed to the diffusion

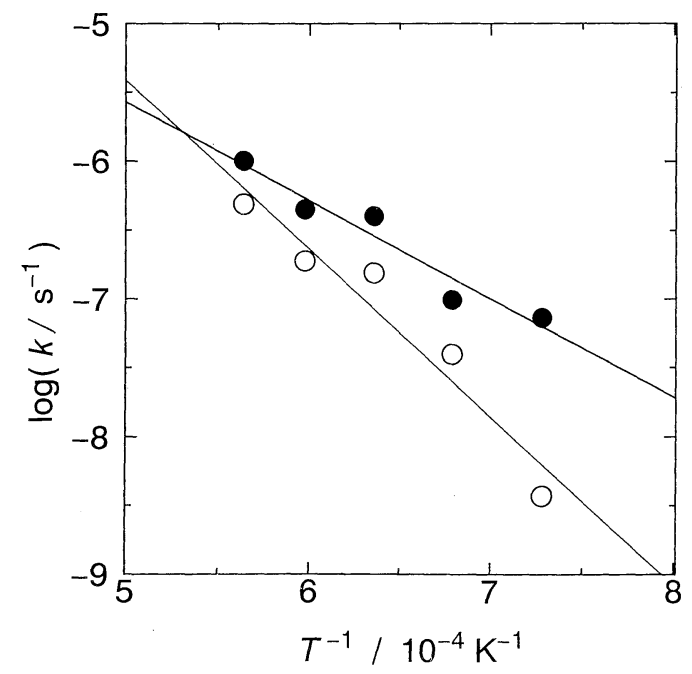

Fig. 7. Arrhenius plots of rate constant $k$ for oxidation of lowoxygen fiber $(\bigcirc)$ and Nicalon fiber 
of oxygen ion. Because the oxide film of $\mathrm{SiC}$ fiber has many micropores, $\mathrm{O}_{2}$ molecules can diffuse through the pores to the unreacted core. The rate constant $k$ for Nicalon NL200 also is presented in Fig. 7. Nicalon has the larger value of $k$ and the lower activation energy of $137 \mathrm{~kJ} / \mathrm{mol}$ in comparison with the low oxygen fiber. This result may be explained by the rapid gaseous diffusion through the pores, because Nicalon, XRD pattern of which shows the highly disordered arrangement of atoms, ${ }^{14)}$ forms the much porous oxide film. On the other hand, the low oxygen fiber, which is microcrystalline, is considered to form the silica film with smaller size of pores. Consequently, $k$ is small and the activation energy is high for the low oxygen fiber, because of difficulty in the gaseous diffusion. Thus, the reduction of oxygen in the polymer-derived $\mathrm{SiC}$ fibers is effective for suppression of the high-temperature pyrolysis ${ }^{12)}$ and for improvement of the oxidation resistance.

\subsection{Reduction in strength of oxidized fiber}

Although polymer-derived $\mathrm{SiC}$ fibers tend to pyrolize at high temperatures, the oxide film should restrict the generation of $\mathrm{SiO}$ and $\mathrm{CO}$ from the core. ${ }^{15)-19)}$ Nevertheless, XRD patterns in Fig. 3 show that the core of the fiber pyrolized slightly during oxidation. The pyrolytic reaction seems to proceed mainly at the early stage before the fiber is completely surrounded by the oxide film. The pyrolysis results in the growth of $\beta$-SiC crystallites and the reduction of the strength of the core fiber as shown in Fig. 5. In a polycrystalline ceramic with smaller grains, the follwing relation was derived between the tensile strength and the crystal size: ${ }^{30}$

$$
\sigma=a+b d^{-1 / 2}
$$

where $a$ and $b$ are constants, and $d$ is the mean diameter of crystals. This equation is similar to a HallPetch's relation which holds between the yield strength and the grain size of metal.

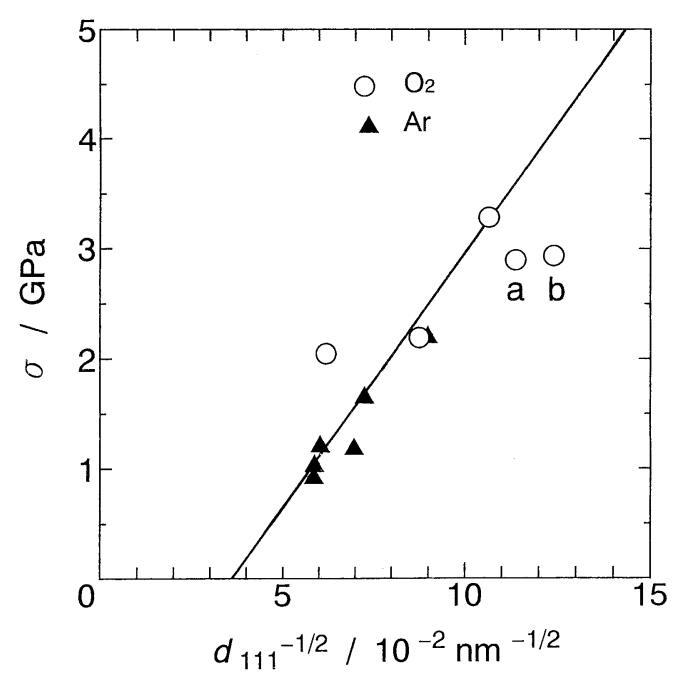

Fig. 8. Tensile strength of low-oxygen fiber heated in $\mathrm{O}_{2}(\mathrm{O})$ and in $\operatorname{Ar}(\mathbf{\Lambda})$ at various temperatures as function of apparent size of $\beta$-SiC crystals.
Figure 8 shows the relationship between $\sigma$ and $d^{-1 / 2}$ for the oxidized fiber together with the fiber heat-treated in $\mathrm{Ar},{ }^{12)}$ where $d$ of $\beta$-SiC crystal was evaluated from the diffraction intensity at (111), using a Scherrer's equation. The experimental data approximately follow Eq. (7). It is noted that the strength of the fiber oxidized at low temperatures (plots $\mathrm{a}$ and $\mathrm{b}$ ) is much smaller than the extrapolated value. This result suggests that the oxidation plays a role in weakening of the fiber for reasons other than the crystallization to $\beta$-SiC. Polymer-derived $\mathrm{SiC}$ fibers are the microcrystalline mixture of $\beta$ - $\mathrm{SiC}$ and free carbon. ${ }^{21)}$ Free carbon is selectively oxidized because of ease of oxidation. The selective oxidation of free carbon leads to the formation of flaws on the surface of the core. In Nicalon oxidized at low temperatures, such flaws came to a source of the fracture. ${ }^{18)}$ Thus, the reduction in strength is considered to be caused by the combination of the crystal growth and the flaw formation.

\section{Conclusion}

The oxidation of the low oxygen fiber prepared by the electron radiation method was investigated in $\mathrm{O}_{2}$ for $72 \mathrm{ks}$ at temperatures from 1373 to $1773 \mathrm{~K}$. Following results were obtained.

(1) The oxide film was amorphous silica below $1573 \mathrm{~K}$ and crystallized to cristobalite above $1673 \mathrm{~K}$. The core crystallized slightly to $\beta$-SiC, accompanying with the formation of amorphous free carbon.

(2) The oxidation rate followed the contractingdisc formula for diffusion control. The activation energy was $234 \mathrm{~kJ} / \mathrm{mol}$. The oxidation is considered to be controlled by the gaseous diffusion through the micropores in the silica film.

(3) The oxide film suppressed the pyrolysis of the core. The tensile strength of the fiber was related to the reciprocal of the square root of the mean diameter of $\beta$-SiC crystal. However, the fiber oxidized at low temperatures had the strength much smaller than the extrapolated value of the fiber heat-treated in Ar.

(4) The reduction of oxygen in the polymer-derived fibers is effective not only for suppression of the high-temperature pyrolysis but also for improvement of the oxidation resistance.

\section{Refernces}

1) C.-H. Andersson and R. Warren, Composites, 15, 16-24 (1984).

2) J. A. DiCarlo, J. Met., 37, 44-49 (1985).

3) L. C. Sawyer, M. Jamieson, D. Brikowski, M. I. Haider and R. T. Chen, J. Am. Ceram. Soc., 70, 798-810 (1987).

4) A. J. Eckel and R. C. Bradt, J. Am. Ceram. Soc., 72, 455-58 (1989).

5) K. M. Prewo, Am. Ceram. Soc. Bull., 68, 395-400 (1989).

6) L. M. Sheppard, Am. Ceram. Soc. Bull., 69, 666-73 (1990).

7) Y. Sasaki, Y. Nishina, M. Sato and K. Okamura, J. Mater. Sci., 22, 443-48 (1987).

8) T. Yamamura, T. Ishikawa, M. Shibuya, T. Hisayuki and 
K. Okamura, J. Mater. Sci., 23, 2589-94 (1988).

9) D. J. Pysher, K. C. Goretta, R. S. Hodder, Jr. and R. E. Tressler, J. Am. Ceram. Soc., 72, 284-88 (1989).

10) M. Takeda, Y. Imai, H. Ichikawa, T. Seguchi and K. Okamura, Ceram. Eng. Sci. Proc., Vol. 12 (1991) pp. 100712.

11) M. Takeda, Y. Imai, H. Ichikawa, T. Seguchi and K. Okamura, Ceram. Eng. Sci. Proc., Vol. 13 (1992) pp. 20917.

12) T. Shimoo, T. Hayatsu, M. Narisawa, M. Takeda, H. Ichikawa, T. Seguchi and K. Okamura, J. Ceram. Soc. Japan, 101, 1379-83 (1993).

13) T. Shimoo, Y. Kakehi, K. Kakimoto and K. Okamura, Nippon Kinzoku-Gakkai-Shi, 56, 175-83 (1992).

14) T. Shimoo, H. Chen and K. Okamura, J. Ceram. Soc. Japan, 100, 929-35 (1992).

15) T. Shimoo, K. Kakimoto and K. Okamura, Nippon KinzokuGakkai-Shi, 56, 785-93 (1992).

16) T. Shimoo, K. Kakimoto, H. Chen and K. Okamura, J. Ceram. Soc. Japan, 101, 204-10 (1993).

17) T. Shimoo, H. Chen, K. Kakimoto and K. Okamura, J. Ceram. Soc. Japan, 101, 295-300 (1993).

18) T. Shimoo, H. Chen and K. Okamura, Nippon Kinzoku-Ga-
kkai-Shi, 57, 652-58 (1993).

19) K. Kakimoto, T. Shimoo and K. Okamura, Nippon KinzokuGakkai-Shi, 57, 957-63 (1993).

20) Y. Hasegawa and K. Hirota, "SiC Ceramics", Ed. by S. Sōmiya and Y. Inomata, Uchida Rokakuho, Tokyo (1988) pp. 211-20.

21) C. Laffon, A. M. Flank, P. Lagarde, M. Laridjani, R. Hagege, P. Orly, J. Cotteret, J. Dixmier, J. L. Miquel, H. Hommel and A. P. Lagrand, J. Mater. Sci., 24, 1503-12 (1989).

22) H. Hashimoto, "Kagaku-Sosetsu, No. 9", Ed. by NipponKagakukai, Tokyo-Daigaku-Shuppankai, Tokyo (1975) pp. 209-36.

23) K. L. Luthra, J. Am. Ceram. Soc., 74, 1095-103 (1991).

24) T. Sata and K. Fujii, Yogyo-Kyokai-Shi, 90, 110-17 (1982).

25) G. Ervin, J. Am. Ceram. Soc., 41, 347-52 (1958).

26) R. F. Adamsky, J. Phys. Chem., 42, 305-07 (1959).

27) E. W. Sukov, J. Am. Ceram. Soc., 46, 14-20 (1963).

28) T. Shimoo, Seramikkusu Ronbunshi, 99, 768-73 (1991).

29) T. Narushima, T. Goto and T. Hirai, J. Am. Ceram. Soc., 72, 1386-90 (1989).

30) K. Hamano and S. Kimura, "Fain Seramikkusu Kisokagaku", Asakurashoten, Tokyo (1990) p. 98. 